\title{
Randomised trial of biofeedback training for encopresis
}

\author{
R N van der Plas, M A Benninga, W K Redekop, J A Taminiau, H A Büller
}

\begin{abstract}
Aims-To evaluate biofeedback training in children with encopresis and the effect on psychosocial function.
\end{abstract}

Design-Prospective controlled randomised study.

Patient interventions-A multimodal treatment of six weeks. Children were randomised into two groups. Each group received dietary and toilet advice, enemas, oral laxatives, and anorectal manometry. One group also received five biofeedback training sessions.

Main outcome measures-Successful treatment was defined as less than two episodes of encopresis, regular bowel movements, and no laxatives. Psychosocial function after treatment was assessed using the Child Behaviour Checklist.

Results-Children given laxatives and biofeedback training had higher success rates than those who received laxatives alone $(39 \% v 19 \%)$ at the end of the intervention period. At 12 and 18 months, however, approximately $50 \%$ of children in each group were successfully treated. Abnormal behaviour scores were initially observed in $35 \%$ of children. Most children had improved behaviour scores six months after treatment. Children with an initial abnormal behaviour score who were successfully treated had a significant improvement in their behavioural profiles.

Conclusions-Biofeedback training had no additional effect on the success rate or behaviour scores. Psychosocial problems are present in a subgroup of children with encopresis. The relation between successful treatment and improvement in behavioural function supports the idea that encopresis has an aetiological role in the occurrence and maintenance of behavioural problems in children with encopresis. (Arch Dis Child 1996;75:367-374)

Keywords: encopresis, biofeedback training, laxatives, Child Behaviour Checklist.

Dr RN van der Plas,

Academic Medical Centre,

G8-245,

1105 AZ Amsterdam, The

Netherlands.

Accepted 22 July 1996

The prevalence of encopresis in otherwise healthy schoolchildren is $1-2 \%$ and it is suggested that encopresis will resolve spontaneously in most children..$^{1-3}$ This explanation may be the reason why many parents of encopretic children postpone an initial visit to the doctor for many years. Parents are often unaware that encopresis is a common childhood problem and ascribe it to poor hygiene, inattention, laziness or stress, whereas shame and cultural taboos are other frequent reasons for this delay. These ideas are supported by the poor agreement among physicians concerning the pathophysiology of encopresis and the lack of studies evaluating different treatments.

Faecal incontinence encompasses encopresis and soiling. Weissenberg introduced the term encopresis to characterise the loss of stool in underwear as the faecal equivalent of enuresis. ${ }^{4}$ The important difference between these two relative objective indices of faecal incontinence, namely encopresis and soiling, is the quantity of faeces lost. Neither term refers to an underlying pathophysiological mechanism. Encopresis is the voluntary or involuntary passage of a quantitatively normal bowel movement in underwear after the age of 4 years, occurring on a regular basis without any organic cause. ${ }^{15}$ Faecal soiling is defined as the involuntary seepage of loose stool resulting in staining of underwear. ${ }^{2}$ Both encopresis and faecal soiling have been associated with constipation, although encopresis may occur without signs of constipation. ${ }^{67}$ Previously, we introduced the term solitary encopresis for children with encopresis without any other sign of constipation. $^{5}$

It is well established that children with faecal incontinence are often socially isolated. ${ }^{8}$ The shame and fear of discovery of their incontinence may lead to social withdrawal, low self esteem, depression, and behavioural problems. ${ }^{129-12}$ Evaluation of whether these behavioural problems have an aetiological role in faecal incontinence or vice versa is needed. ${ }^{25^{1013-15}}$ The negative psychological and social impact for these children is high, however, and requires adequate intervention. ${ }^{131617}$ It is therefore surprising that in contrast to enuresis, for which special training programmes exist, no such attention is given to encopresis. ${ }^{9}$

Biofeedback training has been successful in nence and constipated children with abnormal 
defecation dynamics. ${ }^{18-23}$ Biofeedback training, a treatment strategy based on reinforcement, is derived from psychological learning theory. ${ }^{24}$ In a previous study we reported that about half of children with solitary encopresis have abnormal defecation dynamics. ${ }^{5}$ Additional biofeedback training, therefore, may have positive effects on encopresis and the psychological problems in these children.

A prospective randomised controlled study was therefore conducted to assess the effect of a multimodal treatment with laxatives and additional biofeedback training versus a conservative treatment using laxatives alone, and to evaluate the psychosocial problems in children with solitary encopresis.

\section{Patients and methods}

A two group parallel randomised trial, comparing laxative treatment with biofeedback training and laxative treatment alone, was carried out in children with solitary encopresis. Children were referred by general practitioners, school doctors, paediatricians, and psychiatrists to the Academic Medical Centre, Amsterdam. The study protocol was approved by the medical ethical committee of the hospital. Children or parents, or both, gave written informed consent.

Subject eligibility was based on the presence of solitary encopresis without any other criteria of constipation-that is, normal stool frequency of three times per week or more, no periodic passage of very large amounts of stool, and no palpable abdominal or rectal masses. ${ }^{9} \mathrm{~A}$ previous study showed that children needed to be at least 5 years of age to understand the manometric proceedings and instructions used for biofeedback training. ${ }^{18}$ Children with organic causes of faecal incontinence, such as muscle disorders, anal repair, spina bifida, anal atresia, and Hirschsprung's disease, and those with mental retardation were excluded.

The criterion of a large amount of stool was satisfied if twice the standard amount of stool, shown in a clay model, was reported. Children who never achieved bowel control were defined as having primary encopresis. Those children who were completely toilet trained but subsequently regressed to incontinence were defined as having secondary encopresis.

Each encopretic child underwent a complete investigation at the start and end of the six week intervention period, including a detailed medical history, abdominal and rectal examination, and anorectal manometry. Parents and school teachers completed the Child Behaviour Checklist (CBCL) before treatment started, and at six and 12 months after the last visit in the intervention period.

MEDICAL HISTORY

Children and parents were asked about the frequency of defecation, soiling and/or encopresis, consistency and size of the stool, pain during defecation, family history, and associated symptoms such as abdominal pain, appetite, and enuresis.
PHYSICAL EXAMINATION

Abdominal examination focused on distension and the presence of an abdominal faecal mass. Rectal examination included inspection for fissures or haemorrhoids. Digital examination was performed to provide information about anal tone and the presence of a rectal faecal mass.

ANORECTAL MANOMETRY

This procedure was performed without bowel preparation with a perfused catheter $(4.8 \mathrm{~mm}$ external and $0.8 \mathrm{~mm}$ internal diameter with two side holes $3 \mathrm{~cm}$ apart ${ }^{25}$ ) as described previously. ${ }^{18}$ Briefly, the child is placed in the left lateral position and the proximal side hole of the catheter is placed in the rectum and the distal side hole in the mid-anal canal. Rectal distension is produced using a rectal balloon with a high compliance, tied at the end of the catheter. The catheter is taped to the buttock to avoid displacement during measurement. Pressure is measured by pressure transducers connected to PC Polygraph HR preamplifiers (Synectics Medical) and converted to digital values in a personal computer.

\section{ELECTROMYOGRAPHY}

Electomyography (EMG) of the external anal sphincter (EAS) was recorded by one reference and two differential electrodes. Pregelled disposable neonatal electrocardiogram electrodes were applied over the carefully dried perianal skin, covering the subcutaneous part of the EAS. The reference electrode was located on a thigh. Anorectal variables, as described earlier, ${ }^{18}$ included maximal anal resting tone, measured by stationary pull-through; maximal squeeze pressure, by asking the child to squeeze voluntarily; and the rectal inhibitory reflex, by inflating the rectal balloon with air. The inhibitory reflex was considered to be positive if the anal resting tone decreased with $5 \mathrm{~mm} \mathrm{Hg}$ after distension of the rectal balloon; the sensory threshold was defined by the smallest reproducible distension of the rectal balloon sensed by the child; the critical volume was defined by the amount of air required to produce a sensation of persistent urge to defecate; and defecation dynamics were defined as normal if the integrated EMG and the anal pressure profile of the EAS showed a decrease or no change during attempted balloon expulsion. ${ }^{18}$

\section{CHILD BEHAVIOUR CHECKLIST}

The CBCL is a well known, reliable, and validated checklist for measuring behavioural problems, which was developed and standardised by Achenbach et al. ${ }^{26}$ The behaviour scores are specific for age and gender ( $T$ scores). Normalised $T$ scores were derived from standard scores and allowed comparison of group or individual scores to normative data (mean 50, SD 10) Achenbach et al derived eight syndromes: withdrawn, somatic complaints, anxious/depressed, social problems, thought problems, attention problems, delinquent behaviour, and aggressive behaviour. ${ }^{26}$ These 
syndromes were empirically derived by a first order factor analysis of the problem items of the CBCL. A second order factor analysis of the eight syndromes performed to identify groups of scales that tend to correlate identified two subgroups: (1) internalising problems are those that mainly involve internal conflicts and distress and derive from the withdrawn, somatic complaints, and anxious/depressed syndromes; and (2) externalising problems are those that mainly involve conflicts with other people and their expectations for the child and include syndromes such as aggressive and delinquent behaviour. ${ }^{26}$

Because the total behaviour score is an indicator of the overall level of psychopathology, the 90th centile - that is, a $\mathrm{T}$ score greater than 63 for the total behaviour score, was used for the so called clinical range that discriminates between non-referred children and children referred to mental health centres. The 90th centile ( $T$ score greater than 63 ) is also the cut off point for the clinical range of the internalising and externalising subscales. We used the 98th centile ( $T$ score greater than 70 ) for the eight syndrome scales. The scores of American and Dutch children regarding behavioural problems are comparable and all cut off points are well validated. ${ }^{26}$ The Teacher Report Form is the teacher version of the CBCL. ${ }^{27}$

BIOFEEDBACK TRAINING

Before biofeedback training started normal manometric and EMG tracings were shown to the child, as described previously. Rectal and anal responses were explained. The sensory threshold was determined and subsequent training of sensation was performed by inflating the balloon at different times and requesting the child to contract the EAS whenever rectal sensation was perceived. Subsequently, the balloon was filled with $20 \mathrm{ml}$ air and the patient was instructed to increase abdominal pressure, relax their EAS, and defecate the balloon. If the child did not understand this procedure, the balloon was filled with $50 \mathrm{ml}$ air to show the tracing of a normal relaxation. Visual and verbal reinforcement encouraged the child to modify the response of an adequate expulsion. After accomplishing relaxation of the EAS the child was asked to bear down without visual and verbal feedback. The patient was encouraged to employ the learnt techniques at the slightest urge at home.

\section{TREATMENT}

The intervention period encompassed six weeks of intensive treatment. Children were randomised into two groups - that is, the multimodal group using laxatives and biofeedback training and the conventional treatment group using laxatives alone. During the first visit the child and parent were educated about the different aspects of encopresis, with explicit effort to alleviate guilt and to be nonaccusatory. The children were physically examined and underwent anorectal manometry. After the first visit all children received advice about a high fibre diet and they were instructed to try to defecate on the toilet for five minutes after each meal. Parents were instructed to start daily enemas consisting of $120 \mathrm{ml}$ fluid (Klyx; sodium diotylsulphosuccinate $1 \mathrm{mg}$ sorbitol $250 \mathrm{mg} / \mathrm{ml}$ ) during the first three days at home, after which the children received oral laxatives using Importal (lactitol $\beta$-galactoside sorbitol) $5 \mathrm{~g} / 10 \mathrm{~kg}$ body weight/day, divided into two doses. ${ }^{28}$

There were five outpatient visits of approximately 30 minutes' duration in the intervention period at which laxative treatment was adjusted if necessary and the diary information, including defecation frequency, encopresis, and/or soiling episodes, was evaluated. The biofeedback group received five outpatient visits, including the same conventional treatment as mentioned earlier, in combination with biofeedback training. The biofeedback training sessions lasted for 30 minutes. Each group received as equal as possible attention.

SUCCESS

Treatment was considered to be successful if the child had less than two episodes of faecal incontinence/month without the need for laxatives for a minimum of four weeks. ${ }^{1829}$

FOLLOW UP

Follow up was carried out at six weeks, and six, 12 , and 18 months after the last visit of the intervention period. Follow up was performed either during a clinical visit or by telephone using a standard questionnaire. Parents were asked to complete another CBCL six and 12 months after the last visit.

\section{CONTROLS}

The manometric results were compared with a control group comprising 21 children (16 boys) with a comparable median age of 10 (range 6-17) years. They were recruited from siblings and friends of medical staff and paediatric patients. All children had normal defecation habits and no gastrointestinal complaints.

\section{STATISTICAL ANALYSIS}

Randomisation was carried out with sealed envelopes using a schedule generated by an individual not involved with treatment of the patients.

Median values to assess the clinical symptoms were used because of the skewed distributions of the continuous variables. Manometric variables were compared using median values of each treatment group before and after the intervention. Changes between variables before and after the intervention period were also calculated and expressed as median differences. These values were compared using the Wilcoxon two sample test and compared between both treatment groups. Furthermore, both treatment groups were compared with a control group of 21 children. Success rates at six weeks, and six, 12, and 18 months between laxative treatment alone and biofeedback training were analysed using $\chi^{2}$ analysis. A p value of 0.05 was considered to be significant.

Analysis of the different variables in the CBCL in the study group was performed using the provided computer program. $T$ scores were 
Table 1 Patient characteristics (values are percentages unless otherwise stated)

\begin{tabular}{lll}
\hline Clinical symptoms and patients background & $\begin{array}{l}\text { Biofeedback } \\
\text { training }(n=39)\end{array}$ & $\begin{array}{l}\text { Conventional } \\
\text { treatment }(n=32)\end{array}$ \\
\hline Gender (boys) & 77 & 78 \\
Age (median (range) years) & $9.0(5-16)$ & $9.0(5-14)$ \\
Defecation frequency (median (range)/week) & $8.0(3-16)$ & $9.0(4-18)$ \\
Encopresis and/or soiling (median (range) episodes/week) & $4.0(2-27)$ & $5.5(2-28)$ \\
Abdominal pain & 28 & 28 \\
Painful defecation & 3 & 3 \\
Positive family history & 23 & 22 \\
Primary encopresis & 42 & 41 \\
Special education & 32 & 38 \\
White & 79 & 84 \\
Single parent families & 16 & 25 \\
\hline
\end{tabular}

obtained after correction for age and gender. As we compared the same groups at different time periods, we were able to use the American published cut off points of the CBCL. ${ }^{26}$ Cut off points for the Teacher Report Form were identical to those of the CBCL. ${ }^{30} \mathrm{~T}$ scores were compared using Student's $t$ tests for both treatment groups and between successfully and unsuccessfully treated children. A subanalysis was performed for children with an initial total behaviour score greater than 63 (greater than 90th centile) - that is, the clinical range.

\section{Results}

A total of 334 otherwise healthy patients, ranging from 5 to 16 years of age, attended the gastrointestinal motility unit between February 1991 and February 1994. A group of 88 patients was referred for constipation but only fulfilled the criteria for solitary encopresis. Fifty (57\%) of these children never received medical treatment for their complaints, and were initially treated with a high fibre diet, toilet advice, and laxatives for a period of four weeks before randomisation. Seventeen (34\%) of these children did not enter the study: 15 patients were successfully treated and two withdrew before randomisation. The remaining 71 children were randomised into two groups: 39 received conventional treatment and biofeedback training and 32 received conventional treatment alone.
Initial CBCLs were obtained from 65 children. A total of $60 \mathrm{CBCLs}$ were returned at six months. A total of 23 CBCLs were not returned by parents at 12 months' follow up, therefore the results of the CBCL at 12 months were not included in the analysis.

Baseline characteristics for both groups were comparable (table 1). There were more boys with solitary encopresis and the overall median age was 9 years. Soiling or encopresis episodes, or both, occurred frequently with ranges from 2 to 28 /week. Primary encopresis was observed in $42 \%$ of children receiving biofeedback and in $41 \%$ of those given laxative treatment alone.

\section{ANORECTAL MANOMETRY}

One patient assigned to the biofeedback training group did not return after randomisation; no anorectal manometry was performed in this child. Three other children (two from the biofeedback training group and one from the laxatives alone group) did not complete the intervention programme and no final anorectal manometric measurement could be obtained in these children. Therefore, the manometric results consist of a total of 70 initial and 67 final manometric measurements (table 2).

Anorectal variables before the intervention period showed comparable values for both groups. Maximal anal resting tone decreased in the children in the biofeedback training group after intervention but increased in those in the laxative treatment alone group. Maximal squeeze pressure increased in both groups. The sensory threshold and critical volume after the intervention period were comparable for both groups. All manometric variables showed wide variation and the changes were not statistically significant. Normal defecation dynamics before intervention were observed in 45,53 , and $95 \%$ of children in the biofeedback training, laxative treatment alone, and control groups, respectively. Normal defecation dynamics were present in a significantly greater number of healthy controls $(p<0.01)$ than in children of both treatment groups. At the end of the inter-

Table 2 Manometric variables for both treatment groups before and after the intervention period (values are median (range) unless otherwise stated)

\begin{tabular}{|c|c|c|c|c|}
\hline $\begin{array}{l}\text { Manometric variables (before, } n=70) \text {, } \\
\text { (after, } n=67),(\text { differences, } n=67)\end{array}$ & $\begin{array}{l}\text { Biofeedback training } \\
\text { (before, } n=38 \text { ), } \\
\text { (after, } n=36 \text { ) }\end{array}$ & $\begin{array}{l}\text { Conventional treatment } \\
\text { (before, } n=32 \text { ), } \\
\text { (after, } n=31 \text { ) }\end{array}$ & $\begin{array}{l}\text { p Value between } \\
\text { groups }\end{array}$ & $\begin{array}{l}\text { Controls } \\
(n=21)\end{array}$ \\
\hline \multicolumn{5}{|l|}{ Maximal anal resting tone $(\mathrm{mm} \mathrm{Hg})$} \\
\hline Before & $62.5(18-95)$ & $57(18-99)$ & \multirow{3}{*}{0.22} & \multirow{3}{*}{$55(33-100)$} \\
\hline After & $57.0(24-100)$ & $64(28-107)$ & & \\
\hline Differences & $-1.0(-38-35)$ & $5(-51-50)$ & & \\
\hline \multicolumn{5}{|l|}{ Maximal squeeze pressure $(\mathrm{mm} \mathrm{Hg})$} \\
\hline Before & $149(84-264)$ & $143(62-288)$ & \multirow{3}{*}{0.08} & $180(81-338)$ \\
\hline After & $182(66-373)$ & $152(84-248)$ & & \\
\hline Differences & $24(-90-237)$ & $9(-154-87)$ & & \\
\hline \multicolumn{5}{|l|}{ Sensory threshold (ml air) } \\
\hline Before & $15.0(5-100)$ & $15.0(5-80)$ & \multirow{3}{*}{0.71} & $17(5-60)$ \\
\hline After & $15.0(5-180)$ & $15.0(5-240)$ & & \\
\hline Differences & $-5.0(-45-120)$ & $0(-65-200)$ & & \\
\hline \multicolumn{5}{|l|}{ Critical volume ( $\mathrm{ml}$ air) } \\
\hline Before & $150(60-330)$ & $150(60-300)$ & \multirow{3}{*}{0.68} & $120(60-210)$ \\
\hline After & $150(60-300)$ & $150(60-300)$ & & \\
\hline Differences & $0(-180-120)$ & $0(-90-150)$ & & \\
\hline \multicolumn{5}{|l|}{ Normal defecation dynamics (\%) } \\
\hline Before & $45^{\star}$ & $53^{\star}$ & 0.48 & 95 \\
\hline After & $86 \dagger$ & 74 & 0.22 & \\
\hline
\end{tabular}

${ }^{\star} p<0.01$; a significant difference between the treatment groups (biofeedback training and laxative treatment alone) and the control group.

$t p<0.01$; a significant difference in the biofeedback group, before and after biofeedback training. 
Table 3 Success rates for both treatment groups at the different follow up periods (percentages in parentheses)

\begin{tabular}{llcl}
\hline Follow up & $\begin{array}{l}\text { Biofeedback } \\
\text { training }\end{array}$ & $\begin{array}{l}\text { Conventional } \\
\text { treatment }\end{array}$ & $\begin{array}{l}p \text { Value between } \\
\text { groups }\end{array}$ \\
\hline End intervention $(\mathrm{n}=68)$ & $14 / 36(39)$ & $6 / 32(19)$ & 0.07 \\
6 Weeks (n=68) & $13 / 36(36)$ & $12 / 32(38)$ & 0.91 \\
6 Months (n=66) & $17 / 34(50)$ & $15 / 32(47)$ & 0.80 \\
1 Year $(\mathrm{n}=66)$ & $18 / 34(53)$ & $15 / 32(47)$ & 0.62 \\
1.5 Years (n=67) & $17 / 36(47)$ & $15 / 31(48)$ & 0.92 \\
\hline
\end{tabular}

vention period normal defecation dynamics increased to $86 \%$ in the biofeedback training group $(\mathrm{p}<0.01)$ and to $74 \%$ in the laxative treatment alone group $(p=0.08)$. The presence of normal defecation dynamics at the end of intervention did not differ significantly between the biofeedback training and laxative treatment alone groups $(p=0.22)$

\section{SUCCESS RATES}

At the end of intervention successful treatment was estimated in $39 \%$ of children in the biofeedback group and in $19 \%$ of those in the laxative treatment alone group $(p=0.07)$ (table 3). Follow up at six weeks and six, 12, and 18 months showed comparable success rates for biofeedback training and laxative treatment alone. Comparable treatment outcome was observed for children with normalised and without normalised defecation dynamics (data not shown).

Table 4 Behaviour problems in children with solitary encopresis evaluated with the Child Behaviour Checklist (CBCL) and Teacher Report Form (TRF) before the intervention period

\begin{tabular}{llll}
\hline & $\begin{array}{l}\text { CBCL } \\
(n=65)\end{array}$ & $\begin{array}{l}\text { Within clinical } \\
\text { range\% }\end{array}$ & $\begin{array}{l}\text { TRF }(T \text { score }) \\
(n=65)\end{array}$ \\
\hline Total behaviour score & 58.6 & 35 & 54.3 \\
Externalising & 54.3 & 17 & 51.7 \\
Internalising & 56.9 & 32 & 56.0 \\
Withdrawn & 57.9 & 12 & 57.9 \\
Somatic problems & 58.6 & 3 & 55.6 \\
Anxious/depressed & 57.5 & 13 & 57.0 \\
Social problems & 58.5 & 10 & 58.0 \\
Thought problems & 55.4 & 5 & 53.6 \\
Attention problems & 59.5 & 7 & 55.2 \\
Delinquent behaviour & 56.5 & 3 & 53.6 \\
Aggressive behaviour & 57.1 & 8 & 54.8 \\
\hline
\end{tabular}

Table 5 Mean T scores in successfully and unsuccessfully treated children for the different behavioural profiles ( $B F=$ biofeedback training, $C T=$ conventional treatment)

\begin{tabular}{|c|c|c|c|c|c|c|}
\hline \multirow{2}{*}{$C B C L$ variables } & \multicolumn{3}{|c|}{ Successful patients at six months } & \multicolumn{3}{|c|}{ Unsuccessful patients at six months } \\
\hline & All & $B F$ & $C T$ & All & $B F$ & $C T$ \\
\hline (Before) & $(n=30)$ & $(n=15)$ & $(n=15)$ & $(n=35)$ & $(n=19)$ & $(n=16)$ \\
\hline (After) & $(n=29)$ & $(n=15)$ & $(n=14)$ & $(n=31)$ & $(n=15)$ & $(n=16)$ \\
\hline (Differences) & $(n=28)$ & $(n=14)$ & $(n=14)$ & $(n=30)$ & $(n=14)$ & $(n=16)$ \\
\hline \multicolumn{7}{|l|}{ Total behaviour score } \\
\hline Before & 58.0 & 58.7 & 57.4 & 59.2 & 58.5 & 60.0 \\
\hline After six months & 51.3 & 53.1 & 49.2 & 55.6 & 53.7 & 57.4 \\
\hline Differences (SE) & $-7.4^{\star}$ & -5.8 & -8.9 & $-2.2^{\star}$ & -1.8 & -2.6 \\
\hline & $(1.4)$ & $(2.0)$ & $(1.9)$ & $(1.3)$ & $(2.0)$ & $(1.8)$ \\
\hline \multicolumn{7}{|l|}{ Externalising } \\
\hline Before & 52.0 & 53.7 & 50.2 & 56.2 & 55.2 & 57.5 \\
\hline After six months & 49.1 & 50.6 & 47.4 & 54.1 & 51.5 & 56.5 \\
\hline Differences (SE) & -3.6 & -3.5 & -3.6 & -1.5 & -2.1 & -1.0 \\
\hline & $(1.5)$ & $(2.5)$ & $(2.0)$ & $(1.3)$ & $(1.9)$ & $(1.8)$ \\
\hline \multicolumn{7}{|l|}{ Internalising } \\
\hline Before & 58.1 & 56.9 & 59.3 & 55.9 & 54.9 & 57.1 \\
\hline After six months & 51.6 & 52.9 & 50.2 & 52.9 & 49.7 & 55.9 \\
\hline \multirow{2}{*}{ Difference $s(\mathrm{SE})$} & $-6.9^{\star}$ & -3.9 & -9.9 & $-1.2^{\star}$ & -1.1 & -1.2 \\
\hline & $(1.7)$ & $(2.4)$ & $(2.1)$ & $(1.3)$ & $(2.0)$ & $(1.7)$ \\
\hline
\end{tabular}

$\mathrm{CBCL}=$ Child Behaviour Checklist.

$\star<\mathrm{p} 0.05$.
BEHAVIOURAL PROFILES

Behavioural profiles were analysed using a total of 65 CBCLs (table 4). The total behaviour score in $35 \%$ of children fell within the clinical range- that is, $T$ score greater than 63 and greater than 90 th centile. The mean internalising scores were higher than the mean externalising scores. Clinical ranges for internalising and externalising problems were observed in $32 \%$ and $17 \%$ of children, respectively. The scores of the Teacher Report Form were comparable with the behaviour scores of the CBCL from parents (table 4).

Success rates and behavioural profiles were obtained and compared six months after treatment. The total behaviour scores within the clinical range decreased from $35 \%$ initially to $22 \%$ six months after treatment. The scores for children in the biofeedback training and laxative treatment alone groups were comparable (table 5). Significant differences between children successfully treated and those in whom treatment failed were observed for total behaviour score, internalising problems (table 5), and for withdrawn, thought problem, and attention problem scores (data not shown).

A subanalysis was performed in children with an initial total behaviour score within the clinical range (table 6). As the biofeedback training and laxative treatment alone groups showed similar effects in the overall group, the subgroup analysis was performed regardless of treatment. A similar effect on behaviour was observed in this subgroup, as in the overall group. The $T$ scores of successfully treated children decreased significantly to within normal range values, while a significant improvement only in the total behaviour score was observed in children in whom treatment failed.

\section{FOLLOW UP}

Another two children (biofeedback training) withdrew at six months after the intervention period. One child from the laxative treatment alone group was lost to follow up at 18 months and one from the biofeedback training group, who was initially lost to follow up, returned. There was no specific reason for noncompliance in either treatment groups.

\section{Discussion}

Solitary encopresis, namely faecal incontinence in the absence of any other signs of constipation after the age of 4 years, may have negative psychological and social effects and therefore children with solitary encopresis require treatment, although they are not constipated. In the present study two treatments were evaluated in children with solitary encopresis; a multimodal treatment using biofeedback training and laxative treatment and laxative treatment alone. At the end of the six week intervention period treatment with biofeedback training in encopretic children was more successful than treatment with laxatives alone, but no additional value of biofeedback training was found with further follow up. Behavioural problems were evaluated using the behavioural checklist (CBCL) and showed a 
total behaviour score within the clinical range in $35 \%$ of children. Importantly, successful treatment at six months after intervention resulted in a significant improvement in behaviour scores in the overall group and in children with initial abnormal behaviour scores within the clinical range. Therefore, successful intensive medical treatment is also effective in improving behavioural problems.

We observed an unexplained predominance of boys with solitary encopresis, as reported by others. ${ }^{1914151931}$ Solitary encopresis is a problem without a clear underlying mechanism and controversial ideas exist about its aetiology and treatment as indicated by the relative high median age and the high percentage of children who had never been treated before enrolment in the present study. Others have described similar denial and delay in seeking medical advice and it has been suggested that this is because of the absence of any other sign of constipation. ${ }^{917}$ It is encouraging that $30 \%$ of children who had never been treated could be helped by education, demystification, and a four week course of laxative combined with toilet training.

One third of the children in our study group received special school education, which is in accordance with studies showing high percentages of encopretic children with attention defi- cits, disobedience and moodiness, and learning disabilities. ${ }^{10121732}$ None the less, the important question of whether the behavioural problems are the result of encopresis or vice versa remains.

In this study, in accord with others, anorectal manometry in patients with encopresis showed no impairment of anorectal sensorimotor function compared with that in healthy controls except for abnormal defecation dynamics in about half of the encopretic patients. ${ }^{56181931}$ The abnormal defecation dynamics in children with solitary encopresis may be explained by an acquired control mechanism in which after loss of the first stool in underwear, the child contracts the EAS unconsciously to retain the rest of the stool in the rectum. ${ }^{5}$ Furthermore, we were able to show that significant normalisation of this inadequate habit was achieved with biofeedback training. Many children with conventional treatment also achieved normal defecation dynamics, but this increase was not significant. It is unclear whether the effect of softening the stools by laxatives has a role in this normalisation. We found no correlation between abnormal defecation dynamics and patterns of the behavioural profiles, as reported by others. ${ }^{631}$ Interestingly, the sensory threshold and critical volume were within the normal range, supporting the idea that these children

Table 6 Mean $T$ scores in the subgroup of children with initial behaviour scores in the clinical range (total behaviour, externalising, and internalising $T$ scores $>90$ centile and subitems $>98$ centile) at inclusion and a half year after treatment, divided over successful and unsuccessful treatment

\begin{tabular}{|c|c|c|c|}
\hline & $\begin{array}{l}\text { All (before, } n=24), \\
\text { (after, } n=20)\end{array}$ & $\begin{array}{l}\text { Successful (before, } n=14 \text { ), } \\
\text { (after, } n=13 \text { ) }\end{array}$ & $\begin{array}{l}\text { Unsuccessful (before, } n=10 \text { ), } \\
\text { (after, } n=7)\end{array}$ \\
\hline \multicolumn{4}{|l|}{ Total behaviour score } \\
\hline Before & 68.9 & 67.1 & 71.3 \\
\hline After & 60.2 & 56.7 & 66.6 \\
\hline Differences ( $S E, p$ value) & $-9.0(1.4,<0.001)$ & $-10.6(1.6,<0.001)$ & $-5.9(2.2,0.04)$ \\
\hline \multicolumn{4}{|l|}{ Externalising } \\
\hline Before & 63.3 & 61.1 & 66.3 \\
\hline After & 58.1 & 55.0 & 63.7 \\
\hline Differences (SE, $p$ value) & $-6.0(1.1,<0.001)$ & $-6.7(1.3,<0.001)$ & $-4.7(2.2,0.08)$ \\
\hline \multicolumn{4}{|l|}{ Internalising } \\
\hline Before & 67.5 & 66.4 & 69.2 \\
\hline After & 59.5 & 55.5 & 66.8 \\
\hline Differences (SE, $p$ value) & $-8.2(2.0,<0.001)$ & $-10.6(2.7,0.002)$ & $-3.7(1.5,0.05)$ \\
\hline \multicolumn{4}{|l|}{ Withdrawn } \\
\hline Before & 64.6 & 63.2 & 66.6 \\
\hline After & 61.5 & 57.4 & 69.0 \\
\hline Differences ( $S E, p$ value) & $-4.7(2.4,0.07)$ & $-6.5(3.1,0.06)$ & $-1.3(3.6,0.73)$ \\
\hline \multicolumn{4}{|l|}{ Somatic problems } \\
\hline Before & 62.1 & 62.9 & 60.9 \\
\hline After & 57.3 & 56.9 & 57.9 \\
\hline Differences (SE, $p$ value) & $-3.2(1.9,0.11)$ & $-4.2(2.3,0.09)$ & $-1.1(3.3,0.74)$ \\
\hline \multicolumn{4}{|l|}{ Anxious/depressed } \\
\hline Before & 65.3 & 63.4 & 68.1 \\
\hline After & 59.5 & 56.5 & 65.0 \\
\hline Differences (SE, $p$ value) & $-6.8(1.7,<0.001)$ & $-7.9(2.0,0.002)$ & $-4.7(2.9,0.16)$ \\
\hline \multicolumn{4}{|l|}{ Social problems } \\
\hline Before & 64.8 & 63.4 & 69.9 \\
\hline After & 59.5 & 55.4 & 66.7 \\
\hline Differences (SE, p value) & $-6.5(1.8,0.002)$ & $-5.9(2.2,0.02)$ & $-7.4(3.4,0.07)$ \\
\hline \multicolumn{4}{|l|}{ Thought problems } \\
\hline Before & 61.2 & 61.5 & 60.7 \\
\hline After & 56.9 & 56.0 & 58.4 \\
\hline Differences (SE, $p$ value) & $-4.4(1.7,0.02)$ & $-5.3(2.1,0.03)$ & $-2.7(2.9,0.38)$ \\
\hline \multicolumn{4}{|l|}{ Attention problems } \\
\hline Before & 65.8 & 63.7 & 68.6 \\
\hline After & 59.3 & 54.8 & 67.4 \\
\hline Differences (SE, p value) & $-7.0(1.5,0.002)$ & $-9.4(1.6,<0.001)$ & $-2.6(2.6,0.35)$ \\
\hline \multicolumn{4}{|l|}{ Delinquent behaviour } \\
\hline Before & 61.1 & 60.2 & 62.3 \\
\hline After & 56.8 & 53.5 & 62.9 \\
\hline Differences (SE, $p$ value) & $-4.7(1.7,0.01)$ & $-6.5(2.0,0.008)$ & $-1.3(2.7,0.66)$ \\
\hline \multicolumn{4}{|l|}{ Aggressive behaviour } \\
\hline Before & 63.5 & 61.2 & 66.7 \\
\hline After & 59.2 & 56.6 & 64.0 \\
\hline Differences (SE, $p$ value) & $-5.3(1.1,<0.001)$ & $-5.5(1.2,<0.001)$ & $-5.0(2.1,0.06)$ \\
\hline
\end{tabular}


despite the often heard complaint of the absence of any urge to defecate have normal anorectal sensorimotor function. Several studies have suggested that biofeedback training should be the treatment of choice in children with abnormal defecation dynamics. ${ }^{19} 1$ Moreover, biofeedback training has been proposed as a behavioural treatment and is therefore appropriate in the management of children with solitary encopresis. ${ }^{24}$ As expected biofeedback training resulted in significant normalisation of defecation dynamics. ${ }^{182122}$ Biofeedback training, however, did not result in significantly higher success rates than in the conventional treatment group during follow up, as comparable with others. ${ }^{21}{ }^{33}$ This finding indicates that children with solitary encopresis largely gain from treatment consisting of a combination of attention, toilet training, and laxatives.

The overall success rate of approximately $50 \%$ in both treatment groups, given the strict criteria of success and the duration of symptoms, seems acceptable and is comparable with a study by Nolan et al. ${ }^{34}$ In contrast with others, abnormal defecation dynamics were not predictive of success rates during follow up. ${ }^{21}$ The initial difference in favour of biofeedback training at the end of the intensive intervention period, however, suggests a positive influence of direct anorectal training. It is unclear, given the initial relatively high success rate in the biofeedback group, whether continued biofeedback training would result in higher success rates at follow up. By contrast, the conservative approach encompassing counselling, education, laxatives, and regulation of bowel habits resulted in similar success rates at follow up. ${ }^{31}{ }^{34}$ The primary role of the prescribed laxatives was to soften the stool to achieve effective expulsion during toilet training. Comparison with other studies remains difficult because many studies often lack clear end points, definitions of success, and have included children with constipation. ${ }^{21517} 1935$

The inability to control defecation and subsequent faecal incontinence are often humiliating for the child and may lead to behavioural problems. ${ }^{912}$ Others, however, have stated that the high prevalence of behavioural symptoms is the product of the same forces that lead to encopresis. ${ }^{15}$ Interestingly, only one third of the children had a total behaviour score within the clinical range. ${ }^{96}$ Similarly, others have suggested that only a subgroup of encopretic children has evident behavioural problems. ${ }^{143137}$ These behavioural problems are mainly of an internalising nature, indicating that these children show withdrawn and depressed behaviour and tend to be quiet and have low self esteem. ${ }^{210^{11-12}}$ Importantly, the two different treatments evaluated in the present study resulted in comparable effects on the behavioural profiles. ${ }^{38}$ An additional effect of biofeedback was not observed. These findings suggest that the key to successful treatment lies in the supportive non-accusing approach with demystification, advice about toilet training, and regulation of bowel habits. Importantly, successfully treated children showed a signifi- cant improvement in their behavioural profiles compared with those in whom treatment failed. The main gain was achieved in internalising factors such as withdrawn, thought, and attention problems. This suggests that successful treatment has an important positive influence on a child's self esteem and thereby positively influences the total behavioural problems. By contrast, parental ratings of behaviour at six months may have been influenced by the positive outcome of treatment.

Some $58 \%$ of children with encopresis and an initial total behaviour score within the clinical range ( $T$ score greater than 63 ) were successfully treated, which is similar to that of the overall group. Children who were successful treated had a significant improvement in almost all behavioural profiles with a return to normal range values, while those with failed treatment and initial scores within the abnormal range had a significant improvement only in the total behaviour score, although this was still within the clinical range. All other variables showed no significant change. It is encouraging that children with abnormal behaviour scores were successfully treated by intensive medical treatment and experienced significant improvement of their overall psychological function. ${ }^{313639}$

In conclusion, intensive medical treatment in children with solitary encopresis has positive effects on encopresis and their behavioural profiles. Moreover, patients with a behaviour score in the clinical range, especially if treatment is successful, have significantly improved behavioural profiles. This observation is paramount and supports the hypothesis that encopresis has an aetiological role in the occurrence and maintenance of behavioural problems. ${ }^{353639}$ Therefore, initial treatment of encopresis should start early and include simple behavioural techniques, as well as an explanation and support for the child and parents, sufficient time, and an adequate laxative regimen. ${ }^{213-1531374041} \mathrm{~A}$ broader intervention strategy, including physiological or psychological investigations, may be needed in children in whom treatment is unsuccessful. ${ }^{17314243}$

We are grateful to Dr W B Gunning for helping us to interpret the results of the CBCL.

1 Bellman M. Studies on encopresis. Acta Paediatr 1966; (suppl 170).

2 Rappaport LA, Levine MD. The prevention of constipation and encopresis: a developmental model and approach Pediatr Clin North Am 1986;33:859-69.

3 Olatawura MO. Encopresis. A review of thirty-two cases. Acta Paediatr 1973;62:358-64.

4 Weissenberg S. Uber enkopresis. Z Kinderheilkd 1926;40 674-7.

5 Benninga MA, Büller HA, Heymans HS, Tytgat GN, Taminiau JA. Is encopresis always the result of constipation? Arch Dis Child 1994;71:186-93.

6 Wald A, Chandra R, Chiponis D, Gabel S. Anorectal function and continence mechanisms in childhood encopresis. $f$ Pediatr Gastroenterol Nutr 1986;5:346-51.

Cavanaugh RM. Encopresis in children and adolescents. Am Fam Physician 1983;27:107-9.

8 Taichert LC. Childhood encopresis: a neurodevelopmental-family approach to management. California Medicine, The Western fournal of Medicine 1971;115:11-8.

Medicine, The Western fournal of Medicine 1971;115:11-8.
9 Levine MD. Children with encopresis: a descriptive analysis [review]. Pediatrics 1975;56:412-6.

10 Boon FF, Singh NN. A model for the treatment of encopresis. Behav Modif 1991;15:355-71. 
11 Hoag JM, Norriss NG, Himeno ET, Jacobs J. The encopretic child and his family. $f$ Am Acad Child Psychiatry 1971;10:242-56

12 Levine MD. Encopresis: its potentiation, evaluation, and alleviation. Pediatr Clin North Am 1982;29:315-30.

13 Lowery SP, Srour JW, Whitehead WE, Schuster MM. Habi training as treatment of encopresis secondary to chronic training as treatment of encopresis secondary to chron

14 Friman PC, Mathews JR, Finney JW, Christophersen ER Leibowitz JM. Do encopretic children have clinically Leibowitz JM. Do encopretic children have clinically
significant behavior problems? Pediatrics 1988;82:407-9.

15 Levine MD, Mazonson P, Bakow H. Behavioral symptom substitution in children cured of encopresis. Am $\mathcal{F}$ Dis Child 1980;134:663-7.

16 Landman GB, Levine MD, Rappaport L. A study of treatment resistance among children referred for encopresis. Clin Pediatr (Phila) 1984;23:449-52.

17 Levine MD, Bakow H. Children with encopresis: a study of treatment outcome. Pediatrics 1976;58:845-52.

18 Benninga MA, Büller HA, Taminiau JA. Biofeedback training in chronic constipation. Arch Dis Child 1993;68:126-9.

19 Wald A, Chandra R, Gabel S, Chiponis D. Evaluation of biofeedback in childhood encopresis. 7 Pediatr Gastroenterol Nutr 1987;6:554-8.

20 Loening-Baucke V. Modulation of abnormal defecation dynamics by biofeedback treatment in chronically constipated children with encopresis. F Pediatr 1990;116:214-22.

21 Loening-Baucke V. Biofeedback treatment for chronic constipation and encopresis in childhood: long-term outcome. Pediatrics 1995;96:105-10.

22 Cox DJ, Sutphen J, Borowitz S, Dickens MN, Singles J Whitehead WE. Simple electromyographic biofeedback treatment for chronic pediatric constipation/encopresis: preliminary report. Biofeedback Self Regul 1994;19:41-50.

23 Shepherd K, Hickstein R, Rose V, Nasser C, Cleghorn GJ, Shepherd RW. Faecal incontinence in childhood: a multidisciplinary approach including biofeedback. Aust Paediatr $f 1989 ; 25: 351-5$.

24 Linkenhoker D. Tools of behavioral medicine: applications of biofeedback treatment for children and adolescents. $\mathcal{F}$ Dev Behav Pediatr 1983;4:16-20.

25 Arndorfer RC, Stef J, Dodds WJ, Linehan JH, Hogan WJ Improved infusion system for intraluminal esophageal manometry. Gastroenterology 1977;73:23-7.

26 Achenbach TM, Verhulst FC, Baron GD, Akkerhuis GW. Epidemiological comparisons of American and Dutch children: I. Behavioral/emotional problems and competencies reported by parents for ages 4 to $16 . \mathcal{F} \mathrm{Am}$ Acad Child Adolesc Psychiatry 1987;26:317-25.

27 Achenbach TM, Verhulst FC, Edelbrock C, Baron GD, Akkerhuis GW. Epidemiological comparisons of American and Dutch children: II. Behavioral/ emotional problems reported by teachers for ages 6 to 11. $\mathcal{F A m ~ A c a d ~ C h i l d ~ A d o l ~}$ Psychiatry 1987;26:326-32.

28 Camma C, Fiorello F, Tine F, Marchesini G, Fabbri A Pagliaro L. Lactitol in treatment of chronic hepatic encephalopathy. A meta-analysis. Dig Dis Sci 1993;38:91622.

29 Loening-Baucke V. Factors determining outcome in children with chronic constipation and faecal soiling. Gut dren with chronic

30 Verhulst FC, Van der Ende J. Four-year follow-up of teacher-reported problem behaviours. Psychol Med 1991; 21:965-77.

31 Loening-Baucke V, Cruikshank B, Savage C. Defecation dynamics and behavior profiles in encopretic children. Pediatrics 1987;80:672-9.

32 Stern HP, Lowitz GH, Prince MT, Altshuler L, Stroh SE The incidence of cognitive dysfunction in an encopretic population in children. Neurotoxicology 1988;9:351-7.

33 Gabel S, Chandra R, Shindledecker R. Behavioral rating and outcome of medical treatment for encopresis. $\mathcal{f}$ Dev Behav Pediatr 1988;9:129-33.

34 Nolan T, Debelle G, Oberklaid F, Coffey C. Randomised trial of laxatives in treatment of childhood encopresis. Lancet 1991;338:523-7.

35 McClung HJ, Boyne LJ, Linsheid T, et al. Is combination therapy for encopresis nutritionally safe? Pediatrics 1993; 91:591-4.

36 Sprague-Mcrae JM, Lamb W, Homer D. Encopresis: a study of treatment alternatives and historical and behavioral characteristics. Nurse Pract 1993;18:52-3, 56-63.

37 Gabel S, Hegedus AM, Wald A, Chandra R, Chiponis D. Prevalence of behavior problems and mental health utilization among encopretic children: implications for behavioral pediatrics. $\mathcal{F}$ Dev Behav Pediatr 1986;7:293-7.

38 Cobb DE, Evans JR. The use of biofeedback technique with school-aged children exhibiting behavioral and/or learning problems. $千$ Abnorm Child Psychol 1981;9:251-81.

39 Stern HP, Prince MT, Stroh SE. Encopresis responsive to non-psychiatric interventions, with remittance of familial psychopathology. Clin Pediatr (Phila) 1988;27:400-2.

40 Swanwick T. Encopresis in children: a cyclical model of constipation and faecal retention. Br f Gen Pract 1991;41: 514-6.

41 Landman GB, Rappaport L. Pediatric management of severe treatment-resistant encopresis. 7 Dev Behav Pediat 1985;6:349-51.

42 Stark LJ, Owens-Stively J, Spirito A, Lewis A, Guevremont D. Group behavioral treatment of retentive encopresis. $\mathcal{f}$ Pediatr Psychol 1990;15:659-71.

43 Wald A, Hinds JP, Caruana BJ. Psychological and physiological characteristics of patients with severe idiopathic constipation. Gastroenterology 1989;97:932-7.

\section{Between the ears}

The human capacity for thinking up things to measure is inexhaustible. I bet you didn't know that your left ear drum is probably warmer than your right. Work in America (W Thomas Boyce and colleagues, Archives of Pediatrics and Adolescent Medicine 1996; 150: 518-23) has shown a correlation between this temperature difference and behaviour in both children and monkeys.

Ear drum temperatures were measured by infrared thermometry in 19 well, anaesthetised, 2 year old rhesus macaque monkeys and 18 well, awake, 8 year old children. The monkeys had been briefly separated from their peer group at age 1 year 4 months and at these times blood was taken for cortisol and corticotrophin measurements and their motor behaviour assessed. The children's usual behaviour was assessed using previously validated parent completed questionnaires. There was a significant mean ear drum temperature difference (left warmer than right) of about $0.4^{\circ} \mathrm{C}$ in the monkeys and $0.1^{\circ} \mathrm{C}$ in the children. The size of the left-right difference correlated with agitated motor behaviour on separation in the monkeys and with less behavioural resilience and more aggression, depression, and social withdrawal in the children. They did not test whether the degree of temperature difference was influenced by right or left handedness. What does it mean? The main determinant of ear drum temperature (other than environmental temperature variation) is thought to be its blood supply which varies with sympathetic tone and the right sided sympathetic system seems to be more active than the left. These are very preliminary findings but asymmetry of body temperature could reflect a biological phenomenon which leads to a greater susceptibility to behavioural abnormalities. 